\title{
Pensando as Organizações NÃO-GOVERNAMENTAIS NO BRASIL A PARTIR DA TEORIA da AÇão COMUNiCATIVA dE JÜRGEN HABERMAS
}

Ana Claudia Chaves Teixeira

RESUMO: Este artigo é uma tentativa preliminar de aplicar a Teoria da Ação Comunicativa, apresentada por Jürgen Habermas, para a compreensão de um fenômeno recente no cenário político brasileiro, qual seja, a multiplicação e a visibilidade adquiridas pelas Organizações Não-Governamentais. Neste trabalho, são discutidos alguns conceitos importantes dentro da teoria de Habermas e as apropriações críticas dessa teoria, feitas por Andrew Arato, Jean Cohen e Leonardo Avritzer, ao desenvolverem o conceito de sociedade civil e ao estudarem os processos de democratização na América Latina e na Europa do Leste. Com base nestes autores, são apresentadas, ao final do texto, algumas hipóteses sobre o tipo de atuação e a importância dessas organizações nos dias de hoje.

UNITERMOS: Organizações Não-Governamentais - Democratização - Sociedade Civil Teoria da Ação Comunicativa.

Este artigo tem por objetivo apresentar algumas reflexões preliminares sobre a forma pela qual as Organizações Não-Governamentais estão se multiplicando e sobre a visibilidade adquirida por elas no cenário nacional, desde o fim da ditadura militar, à luz da Teoria da Ação Comunicativa de Jürgen Habermas. A questão central deste trabalho é pensar, em que sentido, a teoria desenvolvida por Habermas pode cola- 
borar para a compreensão deste fenômeno recente da realidacie social brasileira. Trata-se de um exercício, cuja finalidade é problematizar, até que ponto, uma teoria ampla e geral sobre o desenvolvimento da sociedade moderna pode colaborar para o estudo de um caso concreto.

Primeiro, as Organizações Não-Governamentais (ONGs) serão localizadas no contexto atual através de algumas questões que parecem ser mais relevantes. A seguir, serão apresentados alguns dos principais conceitos desenvolvidos por Habermas na Teoria da Ação Comunicativa. Num terceiro momento, será discutida a apropriação crítica da teoria de Habermas, feita por Andrew Arato, Jean Cohen e Leonardo Avritzer, para entender a sociedade civil e o processo de democratização. Por fim, serão articuladas as questões apresentadas na primeira parte à análise teórica desenvolvida nos dois itens posteriores. Esta parte final, ao invés de ser conclusiva, será composta por hipóteses, suscitadas com a leitura, que possibilitarão o desenvolvimento de uma pesquisa empírica posterior.

\section{I}

Durante todo o período de ditadura militar no Brasil, de 1964 a 1985, os grupos de oposição ao regime tiveram uma atuação que pode ser caracterizada como uma "atuação contra o Estado". Não poderia ser diferente. Os distintos movimentos sociais que floresceram ou se desenvolveram nesta época - entre eles, os movimentos de direitos humanos, sindicais, estudantis, de bairro, de saúde, moradia etc. - não tinham nenhum "espaço" para atuarem como parte do (ou junto ao) poder público estatal.

Este quadro foi se transformando, em parte, com a "lenta e gradual abertura política", promovida pelos próprios militares no poder. E, paralelamente, esses movimentos sociais (e seus simpatizantes) buscaram a construção de um projeto alternativo de democracia para o Brasil, que pode ser compreendido como o "lado escondido" do processo de de- 
mocratização (Alvarez, 1994). Uma das facetas deste projeto foi o estabelecimento de ligações entre os movimentos e a arena da política institucional formal, ${ }^{1}$ permitindo que demandas e discursos fossem transformados em itens programáticos nas plataformas de partidos e, ocasionalmente, em políticas públicas. $\mathrm{O}$ vínculo com o Partido dos Trabalhadores, que propôs representar os grupos e classes subalternos, e incorporou ao seu projeto discursos dos movimentos populares, e ainda a formação de conselhos populares nas administrações municipais do PT, são exemplos destas novas ligações.

Além disso, esses movimentos colaboraram para tentar democratizar e expandir esferas públicas oficiais, especialmente depois de 1985. Seja através da tentativa de eleger representantes nas eleições de 1986, que tivessem vínculos com os movimentos populares, seja através dos vários grupos de pressão, formados por ocasião da Constituinte ("lobbies populares"), a fim de que emendas populares fossem aprovadas. $O$ resultado desses esforços para expandir a participação e a representação resultaram em algumas conquistas significativas como, por exemplo, a permissão de que níveis de democracia direta fossem constituídos no sistema político brasileiro.

Não mais sob um regime autoritário, as relações entre o Estado e os distintos atores sociais passaram por transformações. Neste contexto, ao mesmo tempo em que aumentou o número de Organizações Não-Governamentais (ONGs), estudiosos dos movimentos sociais apontaram para o que denominaram o "refluxo" ou "crise" dos movimentos (Doimo, 1994; Scherer-Warren, 1993; Gohn, 1994). Gohn apresenta três tendências marcantes, no início dos anos 90. Primeiro, a "crise de militância [dos movimentos sociais], de participação, de credibilidade

1Outra faceta deste projeto, tão importante quanto a primeira, diz respeito à luta desses movimentos - cada um a seu modo - para transformar as relações sociais desiguais e discriminatórias, procurando generalizar na sociedade brasileira 'a consciência do direito a ter direitos'. 
nas políticas públicas, de confiabilidade e legitimidade junto à própria população" (Gohn, 1994). Segundo, o aparecimento de novas temáticas sobre questões éticas ou de garantia mínima de sobrevivência, como a Ação da Cidadania contra a Fome e pela Vida, o Movimento de Meninos e Meninas de Rua, o Movimento de Aposentados. Enfim, organizações voltadas para questões sobre direitos sociais que nunca foram solucionadas no país. A terceira tendência foi o crescimento do número de $\mathrm{ONGs}$, e as parcerias, intermediadas por elas, entre o poder público estatal e as "comunidades organizadas".

Essas organizações já existiam no Brasil desde o governo militar, mas multiplicaram-se desde o início da Nova República. O trabalho de Assumpção (1993) procura mostrar como as organizações de "assessoria e apoio", a serviço dos movimentos populares, se transformaram em ONGs. A autora observa que os centros de educação popular, criados no final da década de 60 , sofreram um processo de autonomização "enquanto conjunto de instituições e agentes especializados, espécies particulares de profissionais da política". As ONGs de "assistência popular", nos anos 70 e 80 , junto com a Igreja Católica e outros articuladores políticos ajudaram a difundir discursos e práticas comuns por todo o campo dos movimentos populares, seja através da promoção de inumeráveis "cursos de treinamento" para líderes de movimentos guiados pela "educação popular", baseados nos métodos de Paulo Freire, seja através da produção de uma imensa quantidade de materiais de "comunicação popular" como "manuais, boletins, audiovisuais, dramatização etc." (Doimo, 1993, p.92).

Mas foi só na década de 80 que passou a fazer sentido falar em ONGs brasileiras. ${ }^{2}$ Houve, por um lado, a tentativa de encontrar uma identidade comum entre as ONGs latino-americanas e, por outro, a pro-

${ }^{2}$ Antes disso, eram denominadas ONGs apenas as agências financiadoras, freqüentemente estrangeiras, dos centros de assessoria brasileiros.

Temáticas, Campinas, 4(8):167-183, jul./de\%. 1996 
fissionalização crescente dos agentes dessas organizações. $O$ que antes era um serviço voluntário passou a ser uma profissão. Além disso, no final da década de 80 , início da década de 90 , surgiram várias ONGs ambientalistas, e passaram a se autodeterminar como ONGs um vasto número de entidades, que, anteriormente, se reconheciam apenas sob a denominação de filantrópicas (Sherer-Warren, 1994).

Desde 1986, várias ONGs estavam se articulando, quando, em 1991, foi formada a Associação Brasileira de ONGs (ABONG). Nem todas as ONGs brasileiras fazem parte desta associação (apenas 238 - segundo dados obtidos na própria sede da ABONG em outubro de 1995 - das 1010 existentes). ${ }^{3}$ Mesmo porque existem regras para a filiação. As ONGs devem: 1) ser autônomas frente ao Estado, às igrejas, aos partidos políticos e aos movimentos sociais; 2) manter compromisso com a constituição de uma sociedade democrática, incluindo o respeito à diversidade e ao pluralismo; 3) ter um caráter público em relação aos seus objetivos e ação; 4) possuir personalidade jurídica própria como sociedade sem fins lucrativos; 5) ter ao menos dois anos de experiência comprovada. ${ }^{4}$

Face às transformações no cenário político brasileiro, principalmente com a democratização, o "saber técnico" produzido pelas ONGs passou a ser mais valorizado, não apenas pelos movimentos sociais, como também pelo Estado. Tanto foi assim que, no início do ano de 1995, o governo propôs à ABONG participar do Programa Comunidade Solidária, numa espécie de parceria. Esta proposta causou entre os filiados reações distintas de apoio e contestação a esta parceria. Evidenciouse o dilema que Assumpção apontava em seu trabalho. $O$ dilema para essas organizações passou a ser como elas se posicionariam contra o "neoliberalismo", que também valoriza a atuação da "sociedade civil" e

${ }^{3}$ De acordo com levantamento feito por Fernandes (1994).

Estas informações constam do Jornal da $A B O N G$, n. 9, jan/95. 
critica o Estado. O debate interno a elas passou a ser como evitar que não se tornassem "aliviadoras de políticas recessivas" (Assumpção, 1993).

Desta forma, com uma nova conjuntura política, era o momento para que as organizações da sociedade mudassem seus rumos, deixassem a denúncia da institucionalidade política autoritária e a negação em participar dela para assumirem ações propositivas que rompessem com o espírito resistente à institucionalidade. Seguindo as obscrvações de Doimo (1994), podemos perceber que são outros tempos para as ONGs. Se antes elas estavam dirigidas para a educação popular, hoje elas se voltam para a ampliação dos direitos da cidadania, para questões de políticas públicas e de desenvolvimento sustentável. Se antes elas lutavam "contra o Estado", hoje elas procuram participar de forma seletiva da esfera político-administrativa. Se antes elas estavam voltadas para a "pedagogia popular", cada vez mais elas precisam se mostrar eficazes na realização de ações concretas, demonstrando sua competência técnica para a resolução de problemas.

Configurado o quadro no qual as ONGs estão inseridas nos dias de hoje, este trabalho tratará de, a partir da teoria habermasiana da ação comunicativa, discutir as seguintes questões: a) por que as ONGs ganham destaque no cenário político brasileiro após a abertura política; b) por que elas passam pelas transformações apontadas no parágrafo anterior; e, c) por que é um dilema para essas organizações a relação com o poder público estatal.

\section{II}

Segundo Habermas, toda teoria sociológica que pretenda ser uma teoria geral da sociedade deve enfrentar a questão da racionalidade nos planos metateórico, metodológico e empírico. $\mathrm{O}$ autor que melhor 
lidou com a problemática da racionalidade foi Max Weber, pois questionou a fé iluminista no progresso. Para Weber a racionalidade da modernidade diz respeito a fins, cujo telos é a dominação do mundo a serviço dos interesses humanos. O resultado dessa racionalidade não é um novo centro de sentido, depois que a razão dissolve a tradição. Dissolvida a tradição, as cosmovisões religiosas não são substituídas por nada que dê sentido e unidade à vida. Este fenômeno é denominado por Weber de 'desencantamento do mundo'.

O marxismo, influenciado por Weber, de Horkheimer e Adorno observa que o progresso técnico-científico (visto como positivo por Marx) conduziria o proletariado ao completo imobilismo, pois ele estaria sujeito à racionalização e à planificação capitalista (McCarthy, 1987).

Procurando fugir do pessimismo desses autores e fornecer um novo paradigma de compreensão do processo de racionalização, Habermas utiliza-se dos conceitos de ação comunicativa e mundo da vida, e procura entender a articulação entre 'mundo da vida' e 'sistema'. O autor quer perceber os efeitos do processo de racionalização sobre os atores sociais. Ele observa, portanto, duas lógicas que regem a sociedade moderna: uma lógica estratégica do sistema, que organiza o mercado e o Estado; e outra lógica, a da racionalidade comunicativa, que organiza a solidariedade e a identidade no interior do mundo da vida .

Habermas, ao desenvolver o conceito de mundo da vida, analisa a tendência evolutiva do desacoplamento entre sistema e mundo da vida. Por isso, o autor propõe que compreendamos a sociedade simultaneamente como sistema e mundo da vida.

'Este conceito dual de sociedade está baseado numa teoria da evolução social, que distingue entre racionalização do mundo da vida e aumento da complexidade dos sistemas sociais, com a finalidade de captar devidamente, ou seja, de fazer acessivel a uma análise empirica a conexão que Durkheim propôs entre formas de integração social e etapas de diferenciafão sistêmica"(Habermas, 1988, p. 168). 
Habermas afirma que o conceito de mundo da vida não pode ser reduzido somente à perspectiva culturalista, tal como Schütz e Luckman propuseram. Se considerarmos a ação comunicativa, não apenas como um mecanismo de interpretação através do qual se reproduz o saber cultural, mas sim como a forma pela qual os atores, ao se entenderem sobre algo no mundo, participam simultaneamente em interações através das quais desenvolvem, confirmam e renovam seu pertencimento aos grupos sociais e à sua própria identidade, descartamos o caráter unicamente culturalista do mundo da vida. O mundo da vida, para Habermas, compreende, portanto, três componentes estruturais: a cultura, que é " $o$ acervo de saber, em que os participantes da comunicąãa se abastecem de interpretaģōes para entender algo do mundo"; a sociedade, que é composta por "ordenações legítimas através das quais os participantes na interaf̧ão regulam seus pertencimentos a grupos sociais, assegurando com isso a solidariedade"; e a personalidadc, "competência que possibilita um sujeito de ter linguagem e ação, que o capacita de fazer parte de processos de entendimento e afirmar neles sua própria identidade" (Habermas, 1988, p. 196).

Habermas entende a evolução social como um processo de diferenciação que conduziu ao aumento da complexidade do sistema e da racionalidade do mundo da vida, causando uma diferenciação interna no sistema e uma diferenciação entre sistema e mundo da vida. Sucessivamente, foram quatro os mecanismos sistêmicos que ocuparam o primado evolutivo: a segmentação para que houvesse o intercâmbio, a estratificação para a diferenciação do poder, o Estado para a dominação política e o direito formal para estabelecer as relações entre pessoas jurídicas privadas.

O autor obscrva na relação existente entre sistema e mundo da vida: quanto mais diferenciado um sistema social, mais encolhido fica o mundo da vida, convertendo-se num subsistema. Quanto mais complexos os sistemas sociais, mais provinciano o mundo da vida (1988, p. 244). Esse fato se dá não por uma relação de causalidade, mas porque o 
aumento da complexidade de um sistema depende da diferenciação estrutural do mundo da vida. As inovações só ocorrem, se o mundo da vida for suficientemente racionalizado (principalmente a moral e o direito). Só há novos níveis de diferenciação sistêmica quando a racionalização do mundo da vida alcança níveis correspondentes.

A ironia do processo histórico foi que a racionalização do mundo da vida tornou possível um aumento da complexidade sistêmica. O sistema se hipertrofiou até que os imperativos sistêmicos impediram a capacidade de absorção do mundo da vida, fazendo com que ele fosse instrumentalizado por esses imperativos. Houve, então, a polarização de dois tipos de ação: a voltada para o entendimento e a voltada para o êxito, resultando na desconexão entre integração social e integração sistêmica. Conclui Habermas, "O mundo da vida racionalizado possibilita a aparifão e aumento de subsistemas cujos imperativos autonomizados agem destrutivamente sobre esse mesmo mundo da vida" (Habermas, 1988, p. 263)

$\mathrm{O}$ autor desenvolve a questão de como o mundo da vida é delimitado em seu conjunto pela mudança estrutural da sociedade e como ele se transforma à medida que se produz esta mudança. $O$ problema não foi a modernidade cultural em si, como diria Weber, mas a forma seletiva de institucionalização e empobrecimento cultural causados pela modernidade cultural, permitindo a entrada dos meios de controle - dinheiro e poder - em áreas da ação do mundo da vida, que requerem a integração por meio de processos comunicativos. O problema foi a entrada da lógica sistêmica no mundo da vida, processo este que Habermas denominou 'colonização do mundo da vida'. $\mathrm{O}$ autor analisa o fenômeno da 'juridificação' para mostrar os efeitos dessa colonização. E conclui: é preciso impedir que os "âmbitos sociais que dependem de modo funcionalmente necessário de uma integração social através de valores, normas e processos de entendimento, fiquem à mercê dos imperativos sistêmicos dos subsistemas economia e administrafãa" (1988, p. 527). Este processo de evitar a dominação dos impe- 
rativos sistêmicos sobre os âmbitos sociais, nos quais predominam a integração social, denomina-se 'descolonização do mundo da vida'.

Portanto, para compreender as sociedades modernas é preciso observar as relações entre as duas lógicas dos dois subsistemas (a lógica do poder do Estado e a lógica do intercâmbio do mercado) e a relação delas com o mundo da vida. Para Habermas, há uma tensão indissociável entre Estado e mercado e as estruturas do mundo da vida.

Prosseguindo esta reflexão, ao analisar o Estado de bem-estar social, em "A Nova Intransparência", Habermas vê o fim da utopia cristalizada na sociedade do trabalho. $\mathrm{O}$ autor aponta os limites do Estado de bem-estar, revelados a partir da metade dos anos 70. Evidenciouse a contradição entre fins e meios deste projeto social-estatal: o objetivo era criar novas formas de vida estruturadas igualitariamente, mas os instrumentos jurídico-administrativos não foram capazes de atender a essa demanda. O problema foi a falta de qualquer alternativa possível: o capitalismo não poderia viver sem o Estado social, nem poderia coexistir com sua expansão contínua. A única saída, segundo Habermas, seria que "o projeto do Estado social fosse não simplesmente assentado ou interrompido, mas continuasse num nível mais alto de reflexão" (1987, p. 112). O Estado social se voltaria para a sua própria domesticação.

"As sociedades modernas dispõem de três recursos que podem satisfazer suas necessidades no exercicio do governo: $o$ dinheiro, o poder e a solidariedade. As esferas de influência desses recursos teriam que ser postas em um novo equilibrio. Eis o que quero dizer: o poder de integraf̧ão social da solidariedade deveria ser capaz de resistir às 'forgas' dos outros dois recursos, dinbeiro e poder administrativo" (1987, p. 112).

Dessa maneira, um projeto social que estivesse voltado para si mesmo, não trabalharia mais com a utopia da sociedade do trabalho, mas com a utopia de uma sociedade altamente comunicativa, e portanto, amplamente democrática. 


\section{III}

Mas como é possível aproximar estas explicações habermasianas, sobre a colonização do mundo da vida pelo sistema, para tentar entender o processo de democratização brasileiro, e mais especificamente, o papel das ONGs neste processo?

Os autores Arato, Cohen e Avritzer fazem esta aproximação, ao discutirem o conceito de sociedade civil, que Habermas não desenvolve. Segundo Cohen e Arato (1994) o conceito de mundo da vida possui duas dimensões distintas. Há a dimensão das tradições implicitamente conhecidas, imersas na linguagem e na cultura. $\mathrm{E}$ há a dimensão das instituições associativas que reproduzem tradições, solidariedades e identidades. Esta segunda dimensão corresponde melhor ao conceito de sociedade civil.

Cada sociedade tem suas instituições capazes de transmitir cultura, integração e socialização mas, no contexto de um mundo da vida modernizado, só há sociedade civil onde houver garantia jurídica das várias esferas sob a forma de direitos. Isso ocorre porque o Estado moderno e a economia capitalista não apenas complementam o mundo da vida como também tornam as estruturas do mundo da vida instáveis e precárias.

A importância de reconstruir o conceito de sociedade civil utilizando o conceito de mundo da vida diferenciado dos sistemas econômicos e estatal é, justamente, perceber como os direitos, apesar de serem garantidos pelo Estado, não são derivados dele.

A sociedade civil é constituída de movimentos sociais que atuam na esfera da vida pública ou privada, com objetivos no mercado, no Estado ou no próprio mundo da vida. Esses movimentos disputam com o Estado de bem-estar e com as grandes corporações capitalistas a preservação da autonomia e da democracia. Neste sentido, a democracia seria uma forma de institucionalizar no sistema político os princípios da 
racionalidade comunicativa. Seria a tentativa do mundo da vida se sobrepor à lógica dos sistemas e resistir à 'colonização' (Avritzer, 1993).

É importante destacar que Arato e Cohen procuram complementar o instrumental habermasiano, destacando que o mundo da vida não é só defensivo. Eles propõem que a sociedade civil também possui um potencial ofensivo contra a colonizaçào pelo sistema, os movimentos sociais não seriam apenas uma reação à desintegração causada pela modernidade. Habermas nào vê os movimentos sociais aprofundando a racionalização do mundo da vida, o que seria uma estratégia ofensiva. Os autores atribuem este fato à ausência da categoria associação na teoria habermasiana. A ação coletiva aparece, para Habermas, apenas como reação à modernização.

Numa época, na qual as utopias revolucionárias totalizadoras estão desacreditadas, o modelo de sociedade dual apresentado por Habermas permite pensar numa atuação autoreflexiva c autolimitada da sociedade civil. O 'borizonte utópico da sociedade civil' consistiria, segundo os autores, em preservar os limites entre os subsistemas e o mundo da vida. Eles pretendem ir além da análise da sociedade dual entre sistema e mundo da vida, e pretendem mostrar que não há nenhuma razão teórica para excluir a influência comunicativa e democrática que a sociedade civil exerce sobre o Estado e a economia (Arato \& Cohen, 1994, p. 177).

Na sociedade moderna, a coordenação da ação deve permanecer no nível da racionalidade sistêmica (Estado e economia), mas isso não evita que a ação comunicativa possa penetrar nas instituições dessa racionalidade. A questão política passa a ser como introduzir espaços públicos no Estado e nas instituições econômicas, sem acabar com os mecanismos da ação estratégica.

Com a crise do Estado de bem-estar ficou evidente o papel sem precedentes do Estado nos sistemas capitalistas e de como ele dividia funções com o mercado, justificando a importância dos movimentos sociais como fortalecedores da sociedade. 
"(...) o sucesso dos movimentos sociais não é mais concebido enquanto inclusão no poder estatal (reforma) ou enquanto destruição do Estado (revolução). Os segmentos mais reflexivos dos movimentos sociais a vêem enquanto restruturafão da sociedade civil e o controle da economia de mercado e do Estado burocrático"(Arato \& Cohen, 1994, p. 180).

Por isso, os autores concordando com Habermas, propõem a alternativa de continuar reflexivamente o Estado de bem-estar social, que significaria a construção de uma sociedade civil baseada no direito à comunicação e não no direito à propriedade, assim como, a criação de formas de controle social sobre o Estado e a economia compatíveis com o mundo modernizado no qual vivemos.

Reconstruir a noção de sociedade civil, nos termos habermasianos de distinção entre sistema e mundo da vida, permite compreender a atuação de movimentos autolimitados e radicalmente democratizantes presentes na política contemporânea.

Em “Ascensão, Declínio e Reconstrução do Conceito de Sociedade Civil", Arato (1995) destaca como a recuperação do conceito de sociedade civil permitiu compreender fenômenos de transição da ditadura no Leste Europeu e na América Latina. A estratégia estava baseada na organização autônoma da sociedade, na reconstrução de laços sociais fora da esfera estatal e na concepção de uma esfera pública diferente da vislumbrada pela comunicação estatal.

Este autor faz uma série de ressalvas ao uso do conceito de sociedade civil. Três delas são bem pertinentes ao caso brasileiro. Primeiro, Arato distingue entre 'sociedade civil como movimento' e 'sociedade civil como instituição'. Não podemos dizer que a sociedade civil, como esferas institucionalizadas e legalmente diferenciadas, tenha contribuído para a sua própria "libertação". Antes do início da democratização devemos pensar em termos de uma sociedade civil 'como movimento', apenas 'em germe'. 
A segunda observação importante deste autor é que, apesar da lógica da comunicação ter primazia na sociedade civil, isso não significa que o poder e o dinheiro não influenciem o mundo da vida. Nem a sociedade econômica e política podem excluir a comunicação livre, nem a sociedade civil pode excluir o dinheiro e o poder.

Uma terceira observação, pertinente a este trabalho, diz respeito às várias visões concorrentes sobre o conceito de 'sociedade civil', não apenas do ponto de vista teórico, mas político também. Arato aponta que, na Hungria, enquanto todos estavam contra o regime autoritário parecia haver um consenso sobre este conceito. A partir do momento em que foi derrotado o inimigo comum, as diferentes correntes começaram a divergir sobre como seria a melhor forma de conduzir a democratização. Por isso, é necessário destacar os diferentes conceitos de sociedade civil presentes num cenário democratizado.

Avritzer (1994) destaca uma outra vantagem para a utilização do modelo habermasiano na América Latina: permite pensar numa alternativa ao neoliberalismo, já que este rejeita qualquer forma de limitação da 'racionalidade perfeita' do mercado, através de uma forma de desenvolvimento estruturado a partir do Estado. $\mathrm{O}$ modelo neoliberal propõe a abolição das formas estatais de limitação do mercado sem criar formas societárias para desempenhar funções semelhantes. Baseia-se na suposição de que o mercado defende a sociedade.

Pensar, portanto, na atitude ofensiva da sociedade civil, dentro de um modelo de sociedade dual, é uma alternativa para sociedades que se estruturam, predominantemente, em torno do Estado ou do mercado.

\section{IV}

Com base nestas análises, podemos voltar às questões apontadas ao final do item I, formulando algumas hipóteses de pesquisa. Para interpretar o surgimento e o fortalecimento das ONGs após a 'abertura 
política', podemos recorrer à hipótese de que essas organizações - ao menos aquelas que estão filiadas à $\mathrm{ABONG}$ - são uma das formas mais institucionalizadas que a sociedade civil brasileira alcançou até agora. Essas organizações reforçam a tese da utopia do fortalecimento da sociedade civil, através de relações mais democráticas, respeitando a diversidade e o pluralismo. Elas se articulam, sob a forma de redes, como a ABONG, a fim de ampliar a democracia e fortalecer a sociedade (ShererWarren, 1994). Através de múltiplas interligações (mais ou menos conflitivas) - com partidos, sindicatos, movimentos sociais, poder estatal, entidades internacionais e nas relações entre elas mesmas - as ONGs procuram construir uma racionalidade ética, comunicativa, voltada para uma sociedade mais igualitária e justa. Isso pode ser percebido com o exemplo da própria $\mathrm{ABONG}$, onde são articuladas demandas variadas (das mulheres, ecológicas, de pesquisa, de apoio aos movimentos sociais, etc.) em torno de um mesmo compromisso: 'constituir a sociedade democrática'.

Outra hipótese é que as transformações sofridas por elas, no sentido de se tornarem mais eficazes e competentes a cada dia, fazem parte do processo de racionalização do mundo da vida: elas buscam incorporar as técnicas existentes para atingir qualidade no resultado do seu trabalho, e para influenciarem de forma comunicativa e democrática no estado e na economia.

Por fim, como última hipótese, podemos dizer que o dilema ONGs versus Estado é a tentativa de descolonização do mundo da vida, sem que o mundo da vida destrua o Estado e o mercado. Em outras palavras, podemos dizer que as $O N G$ s buscam uma forma de atuação que seja autolimitada, ao mesmo tempo, que ofereça alternativas ao neoliberalismo, exigindo que o Estado cumpra seus deveres e desmentindo a tese de que o mercado defenderia a sociedade.

As conseqüências deste tipo de atuação não são previsíveis. Não podemos prever se as ONGs, ao valorizarem tanto a eficácia dos resul- 
tados, não perderão uma das características fundamentais para os movimentos 'pré-abertura', qual seja, a comunicação livre e democrática entre todos os participantes do movimento. Não podemos prever também, até que ponto, o 'diálogo' com o Estado e o mercado não poderão transformar as ONGs em entidades também colonizadas pelo dinheiro e poder. Esses parecem ser os maiores desafios enfrentados por essas organizações. Resta ao pesquisador problematizar essas hipóteses através de um estudo empírico e ter sensibilidade para perceber as possíveis conseqüências da atuação das ONGs brasileiras.

ABSTRACT: This article aims to apply the Theory of Communicative Action of Jürgen Habermas to understand the proliferation and visibility of Non Governamental Organizations in Brazil. Some important concepts on the theory of Habermas and the studies of Andrew Arato, Jean Cohen and Leonardo Avritzer, about the concept of civil society and the recent democratization process in Latin America and West Europe, are discussed. At last, some hypothesis about the NGOs are introduced.

KeYwords: Non Governamental Organizations - Democratization - Civil Society Theory of Communicative Action.

\section{BIBLIOGRAFIA}

ALVAREZ, S. "Reweaving the Fabric of Collective Action: social Movements Webs, Post-Liberal Political Mediations, and Challenges to 'Actually Existing Democracy", 1994 (mimeo).

ARATO, A. Ascensão, Declínio e Reconstrução do conceito de sociedade civil - Orientações para novas pesquisas. RBCS, n. 27, p. 18-27, 1995.

ARATO, A., COHEN, J. Sociedade Civil e Teoria Social. In: AVRITZER, L. Sociedade Civil e Democratização. Belo Horizonte: Del Rey, 1994. 
ASSUMPÇÃO, L. L. A Invenção das ONGs - do servifo invisivel à profissão sem nome. Rio de Janeiro. Tese (Doutorado em Antropologia Social), Universidade Federal do Rio de Janeiro.

AVRITZER, L. Além da dicotomia Estado/Mercado. Novos Estudos CEBRAP, São Paulo, n. 36, p. 213-222, 1993.

DOIMO, A. M. Movimento Popular no Brasil pós-70: Formação de um Campo Ético-Politico. São Paulo, 1993. Tese (Doutorado) - Universidade Estadual de São Paulo.

. ONGs no Brasil pós-70: da educaf̧ão popular à luta pela cidadania, trabalho apresentado na 46a Reunião Anual da SBPC, Vitória-ES, 1994.

FERNANDES, R.C. Privado porém público - O terceiro setor na América Latina. 12a. ed. Rio de Janeiro: Relume-Delumará, 1994.

GOHN, M. G. Mudança Social, Novos Movimentos Sociais e Cooperação Internacional, UNICAMP, 1994 (mimeo).

HABERMAS, J. A Nova Intransparência, Novos Estudos CEBRAP, São Paulo, n. 18, p. 103-114, 1987.

- Teoria de la Ación Comunicativa, v. II. 2 fed. Madrid: Taurus, 1988, $618 \mathrm{p}$.

McCARTHY, T. La Teoria Critica de Jürgen Habermas. 1 fed. Madrid: Tecnos, $1987,479 \mathrm{p}$.

SHERER-WARREN, W. Redes de Movimentos Sociais. $1 f$ ed. São Paulo: Loyola, 1993, 141 p.

. Organizações Não-Governamentais na América Latina: seu papel na construção da sociedade civil. São Paulo em Perspectiva, São Paulo, v. 8, n. 3, p. 6-14, 1994. 